\title{
Refusals: Opening the Difference in Dialogue
}

\section{Special Editors: Arvind Mandair \& Cosimo Zene}

The collection of articles in this special issue of Social Identities were presented in two separate panels of the international conference on 'Dialogue and Difference' which took place at the University of London's School of Oriental and African Studies between 12 and 14 September 2001. The idea behind these panels-respectively entitled 'Is it Good to Talk?: Refusals of Dialogue' and 'Dialogues Between Cultures and Civilizations' - was to draw attention to the fact that for some dialogue may not exist even in the middle of a conversation or under the circumstances created by contemporary globalization. Indeed for those who exist on the wrong side of the power equation, dialogue, viewed as the need to respond and to respond automatically in a conversation, and in thus responding one's selfrepresentation as other, may in fact be a mechanism of domination and subjection, a mechanism for levelling the difference of conversant subjects to an identity that can be reproduced at will. As a way of resisting this levelling of difference, cultures and individuals have often adopted the paradoxical strategy of entering into discourse by first refusing dialogue. Such refusals are not necessarily to be understood as the eradication of dialogue, but rather signal ways of entering into dialogue under more conducive conditions. From this perspective the strategy of refusal can also be seen as a way of opening a dialogue between cultures and civilizations without repeating past imperialisms. In different ways the papers in this issue have tried to express the positivity of saying no as a way of affirming and keeping the possibility of dialogue open.

Salman Sayyid's article 'After Babel: Dialogue, Difference and Demons' uses the example of Muhammad Khatami's 1998 interview with CNN. During the interview Khatami, who was then President of Iran, used the work of Tocqueville to demonstrate the homology between principles that were foundational to the Islamic Republic of Iran and the United States. Khatami's intervention aimed at refusing the media's terms of conversation which normally reproduced the stereotype of Iranian

Dr Arvind Mandair, Department of Philosophy and Religion, Hofstra University, Hempstead, New York 11549, USA. Email: arvindmandair@hotmail.com

Dr Cosimo Zene, Study of Religions Department, School of Oriental and African Studies, University of London, London, UK. Email: ZC@soas.ac.uk 
fundamentalism versus US freedom. In his article 'Echos-Monde and Abrasions: Translation as a Form of Dialogue', Keijiro Suga critiques the conception of globalization that emerged after $9 / 11$ by deploying Alphonso Lingis' powerful concept of 'the community of those who have nothing in common' and Edouard Glissant's notion of 'world-echoes' as moves that resist the totalizing global economy by creating an opaque linguistic sphere inhabited by numerous silenced noncommunities around the world. In this 'omniphone' space translation becomes a form of dialogue that cultivates transversal connections between communities who have nothing in common.

Articles by Tingyang Zhao, Stephan Feuchtwang and Eske Mollgaard cultivate the possibility of an encounter between Chinese civilizations and the West. By way of reference to the UN and the EU, Zhao posits the Chinese theory of All-under-Heaven as a possible philosophy for world-governance that is more appropriate in the current context than 'international relations'. Eske Møllgaard's article 'Dialogue and Impromptu Words' explores the seeming incommensurability of Western philosophy and Chinese wisdom. Through a critique of the Western notion of dialogue which remains tied to a form of universality that reduces the other to a subaltern position, Møllgaard develops a non-dialogical notion of universality based on Zhuangzi's impromptu words. In his article 'Between Civilizations: One Side of a Dialogue', Stephan Feuchtwang deploys an ancient Chinese slogan hua ren wen, yi cheng tianxia (activate and spread the intrinsic pattern in people to complete the universe) to ask how we can negotiate between two civilizations so that the content of one remains an open one in which knowledge of all claims to universality can be tested by research, argument and interaction. Reflecting on the possibility of a positive and critical anthropological knowledge raises the question as to what is and is not negotiable in maintaining the space for academic knowledge of cultural difference.

Kyoo Lee's article 'The Other of Dialogue: Opening Silences of the Dumb Foreigner' explores the possibility and the resources of silence as it is disclosed in what she calls the 'disrelational ontology' of language. There is a certain dialogic inadequacy, a dumb foreigner in all of us, Kyoo Lee argues. By taking this lack seriously silence can be approached not as a mystified non-language but rather as a universal speech act. The power of silence can be seen as a pointer towards an ethical dialogue. Kazuyasu Ochiai's article "I have Nothing Special to Say" On the Invisible Violence of Cogitas Ergo Es in Intercultural Dialogue' presents a critique of anthropology's desire to define, identify and install polarized entities such as self and other. Instead the author uses the example of a Japanese self as an example of a subject that is fluid and is constantly remade in the process of relating with other selves. Ochiai thus points out the importance of recognizing the failure of achieving total understanding in intercultural dialogues.

\section{Acknowledgements}

The papers in this special issue of Social Identities were originally presented at an international conference on Dialogue and Difference, held at the University of 
London's School of Oriental and African Studies, 12-14 September 2001. The conference organizers, Arvind Mandair and Cosimo Zene, are the guest editors of this issue and would like to formally thank the following sponsors for their generous support: Sikh Research Foundation (UK); Panesar Plahe SEWA Trust; Japan 2001; SOAS Research Committee. 